\title{
ANÁLISE DE SUSTENTABILIDADE DO ETANOL 2G E BIOENERGIA DA CANA
}

\author{
Ana Carolina Catolico ${ }^{1}$
}

Renata Oliveira ${ }^{2}$

Luciana Crivelare ${ }^{3}$

Amanda de Oliveira ${ }^{4}$

\begin{abstract}
RESUMO
A ampliação da demanda por novas fontes energéticas renováveis e que permitam reduzir a dependência dos combustíveis fósseis, criou um mercado oportuno para o desenvolvimento de biocombustíveis, destacando-se o etanol de primeira e segunda geração proveniente da canade-açúcar. A partir desta temática, o presente artigo elabora uma análise de sustentabilidade do etanol $2 \mathrm{G}$ tomando como base seus aspectos ambientais, sociais, econômicos e logísticos. A análise foi fundamentada na experiência nacional e em estudos de cenários já obtidos em outros países, mas quem levaram em consideração as peculiaridades do território nacional, o que faz com que suas implicações sejam únicas. Ambientalmente, o bioetanol gera mais energia do que consome e reduz a emissão de gases do efeito estufa, socialmente ainda utiliza grande concentração de mão-de-obra barata, apesar da tendência à mecanização e da exigência de mão de obra qualificada. Já economicamente ganha-se pela utilização de uma biomassa de baixo custo. O Brasil possui grandes vantagens na produção de biocombustíveis, em especial do etanol, mas para concretizar essas estimativas faz-se necessário apoio através de incentivos públicos à pesquisas, além do desenvolvimento de novas tecnologias que complementem as já existentes. Só assim este setor poderá se estabelecer definitivamente de forma competitiva no mercado.
\end{abstract}

PALAVRAS-CHAVE: Sustentabilidade. Etanol. Cana.

\section{ANAL YSIS SUSTAINABILITY OF 2G ETHANOL AND BIOENERGY OF CANA}

\footnotetext{
ABSTRACT

The expansion of demand for new renewable energy sources and the need to reduce dependence on fossil fuels has created an opportune market for the development of biofuels, especially the first ethanol and second generation from the sugarcane. From this theme, this paper develops an ethanol $2 G$ sustainability analysis view based on their environmental, social,

${ }^{1}$ Engenheira de Petróleo/ Universidade Federal do Rio de Janeiro/ anacatolico@gmail.com

${ }^{2}$ Bióloga/ Universidade Federal do Rio de Janeiro/.luciana.crivelare@poli.ufrj.br

${ }_{3}^{3}$ Geógrafa/ Universidade Federal Rural do Rio de Janeiro/ luciana.crivelare@poli.ufr.br

${ }^{4}$ Gestora Ambiental / Universidade de São Carlos / amandasoliveira@gmail.com
} 


\section{Periódica Eletrônica

economic and logistical aspects. The analysis was based on national experience and scenario already studies obtained in other countries, but taking into account the peculiarities of Brazil, which makes its unique. Environmental bio-ethanol generates more energy than it consumes and reduces the emission of greenhouse gases, socially still uses large concentration of cheap labor, despite the trend towards mechanization and skilled labor requirement. Economically, the benefit is to use a low cost biomass. Brazil has great advantages in the production of biofuels, particularly ethanol, but to implement these estimates it is necessary support through public incentives for research, and the development of new technologies that complement the existing ones. Only then, this sector can definitely set competitively in the market.

KEYWORDS: Sustainability. Ethanol. Cane.

\section{ANÁLISIS DE ETANOL Y SOSTENIBILIDAD 2G BIOENERGY DE CANA}

\section{RESUMEN}

La expansión de la demanda de nuevas fuentes de energías renovables y para reducir la dependencia de los combustibles fósiles ha creado un mercado propicio para el desarrollo de biocombustibles, especialmente el primero de etanol y segunda generación de la caña de azúcar. A partir de este tema, este trabajo se desarrolla un análisis vista $2 G$ sostenibilidad de etanol en base a su medio ambiente, social, económico y logístico. El análisis se basó en la experiencia nacional y estudios de escenarios ya obtenidos en otros países, pero teniendo en cuenta las peculiaridades del país, lo que hace que sus implicaciones son únicos. Bioetanol ambiental genera más energía de la que consume y reduce la emisión de gases de efecto invernadero, social sigue utilizando gran concentración de mano de obra de mano de obra barata, a pesar de la tendencia hacia la mecanización y la exigencia de mano de obra calificada. Desde costo se obtiene mediante el uso de una biomasa de bajo coste. Brasil tiene grandes ventajas en la producción de biocombustibles, especialmente el etanol, sino para poner en práctica estas estimaciones, es necesario apoyar a través de incentivos públicos para la investigación y el desarrollo de nuevas tecnologías que complementan los ya existentes. Sólo entonces puede este sector está definitivamente establecido de manera competitiva en el mercado.

PALABRAS CLAVE: Sostenibilidad. Etanol. Caña.

\section{Introdução}

Nas últimas décadas pode-se observar um grande aumento da frota de veículos leves em território nacional. Com a queda de competitividade do etanol frente aos combustíveis fósseis, este abastecimento tem sido feito basicamente através da gasolina. Porém nossa produção de gasolina não é suficiente para atender a demanda interna, obrigando o país a importar combustível a volumes crescentes. Sendo assim, torna-se indispensável a redução da dependência do petróleo, o que pode ser feito através do incentivo ao mercado de etanol.

O Brasil é o país que mais domina a tecnologia de produção do etanol. A exploração de cana-de-açucar existe desde os tempos coloniais para a 


\section{Periádica Eletrânica

produção de açucar e cachaça, e a partir de 1970, com o ProÁlcool, o país passa a explorar também a capacidade produtiva do etanol como combustível. O uso em escala industrial do etanol é visto mundialmente como ambientalmente correto para a matriz energética. Segundo o CETESB, se toda a frota nacional fosse abastecida a álcool, a poluição do ar seria reduzida de $20 \%$ a $40 \%$.

O Brasil é conhecido por ser um dos maiores produtores mundiais de etanol, gerando anualmente cerca de 30 bilhões de litros deste combustível. No entanto, esses números podem ser ainda maiores, visto que, a primeira geração de etanol, mais conhecida como $1 \mathrm{G}$, é obtida por técnicas convencionais onde se extrai apenas um terço da energia da planta.

O cenário do mercado atual de etanol poderá sofrer grandes mudanças com a inserção de uma nova tecnologia: etanol celulósico ou de segunda geração (2G). Este biocombustível é produzido a partir da biomassa gerada pelos resíduos agroindustriais como cana, milho e trigo. A técnica utiliza hidrólise enzimática onde a celulose contida nestes resíduos é quebrada por enzimas. Como faz uso de resíduos para a matéria-prima, a produção não necessita de novo corte de plantas, nem de novas áreas de plantio, além de não competir com a produção de comida. $O$ incremento na produção de etanol pode chegar a $50 \%$ em relação ao nível atual.

\section{Revisão Bibliográfica}

Depois de anos de exploração intensiva em energia solar fossilizada através de carvão, petróleo e gás natural, a energia fotossíntética vem retomando seu espaço trazendo uma nova dinâmica ao agronecócio e ao contexto energético internacional. A captação e armazenamento de energia solar nos vegetais volta ao foco das pesquisas, impulsionando a bioenergia da cana brasileira.

A bioenergia é um caso particular de energia química, definida como toda e qualquer forma de energia associada a formas de energia química acumulada mediante processos fotossintéticos recentes. As biomassas, por sua vez, são os recursos naturais que dispõem de bioenergia e que podem ser 
processados para fornecer formas bioenergéticas mais elaboradas e adequadas para o uso final. Pode-se citar como exemplos de bioenergia: lenha e resíduos de serraria, carvão vegetal, biogás resultante da decomposição anaeróbia de lixo orgânico e outros resíduos agropecuários, biocombustíveis líquidos e a bioeletricidade (queima de combustíveis como o bagaço e a lenha).

O etanol de primeira geração pode ser produzido em escala industrial a partir de biomassas como cana-de-açúcar, sorgo, beterraba ou milho. Após a colheita, a matéria-prima é levada para a lavagem e logo depois para um triturador e esmagador. Em seguida ocorre um processo de separação, onde são utilizadas enzimas para separação dos açúcares presente na matériaprima. Os açúcares separados são transformados em etanol por um processo de fermentação, utilizando-se microorganismos específicos, e finalmente ocorre uma purificação em que o etanol é destilado, e daí seguindo para à distribuição.

O uso de etanol traz consigo uma série de vantagens como a menor dependência de combustíveis fósseis importados e de suas flutuações de preço, menor emissão de poluentes e utilização dos subprodutos da cana no seu próprio ciclo produtivo.

O bagaço é o subproduto com maior reaproveitamento energético, uma vez que é utilizado nas caldeiras como fonte de produção de vapor e consequente geração de energia elétrica obtida pela sua queima. Um outro residuo gerado é o vinhoto, que pode ser usado como fertilizante da terra utilizada no plantio. É importante lembrar que durante o corte da cana, ainda utiliza-se em alguns locais a queima, o que acarreta emissão de $\mathrm{CO}_{2}$. Porém essa emissão é compensada durante a fase de crescimento da cana, onde a planta absorve $\mathrm{CO}_{2}$, havendo um equilibrio na geração deste gás para a atmosfera.

Segundo os dados da CTC $^{2}$ na safra de 2008/2009 o Brasil gerou 160 milhões de toneladas de bagaço, destes aproximadamente $75 \%$ foi utilizado na produção de energia elétrica por cogeração juntamente com 5\% da palha disponível nas usinas sucroalcooleiras, representando cerca de $3 \%$ da matriz 


\section{Periódica Eletrônica

elétrica brasileira. O excedente de bagaço das usinas torna-se uma opção para a produção de etanol de segunda geração

O etanol 2G entra no ciclo produtivo da usina através do bagaço da cana, que será seu principal insumo. A produção de E2G se dá a partir de material lignocelulósico (MLC) proveniente da biomassa. Diversas fontes vem sendo usadas como palha de milho, de trigo e de arroz, resíduos de cana-deaçúcar, bagaço de sorgo sacarino, gramíneas, resíduos florestais. No Brasil, como usamos a cana como matéria-prima para o etanol $1 \mathrm{G}$, é o seu resíduo que vem sendo o foco dos estudos.

As principais tecnologias usadas para a produção do E2G são: a hidrólise seguida de fermentação e a gaseificação de materiais lignocelulósicos. A hidrólise pode ser realizada por processos ácidos, com solventes orgânicos (metanol, etanol ou acetona) com um catalisador ácido (ácido sulfúrico ou clorídrico) ou através de enzimas (sacarificação). A gaseificação, por sua vez, caracterização pela conversão em altas temperaturas da biomassa em gases $\left(\mathrm{CO}_{2}, \mathrm{H}_{2}, \mathrm{CO}\right.$ e vapor d'água), obtendo como resultado a geração de eletricidade em ciclo combinados e a produção de combustíveis líquidos.

Os governos de países como China, EUA, os da União Européia e o Brasil vêm ao longo dos últimos anos realizando investimentos em pesquisa e desenvolvimento de novas tecnologias para a produção do E2G. Isto porque, sua viabilização comercial representa um grande passo em direção a sustentabilidade ambiental e segurança/independência energética. Alguns dos instrumentos de política pública utilizados pelos governos para incentivo estão sendo os mandatos de mistura obrigatória, incentivos fiscais e subvenções para P\&D.

O processo de difusão das tecnologias de produção estão em fase inicial, com as primeiras plantas pioneiras acabando de produzir os primeiros litros de etanol em 2014. O maior passo para a produção de bioetanol no Brasil ocorreu em 2007 quando o Laboratório de Tecnologia Enzimática do Instituto de Química da UFRJ conseguiu achar uma mistura de enzimas capaz de realizar a hidrólise de celulose de forma tão eficiente quando as enzimas 
fornecidas pelas companhias internacionais. O alto custo de importação destas enzimas representa uma barreira para a produção nacional de etanol 2G.

O etanol 2G, após anos de desenvolvimento tecnológico, atingiu o estágio de plantas comerciais. No Brasil já existe uma capacidade instalada de 140 milhões de litros por ano. Apesar do conhecimento sobre as técnicas físicas, químicas e biológicas produtivas, estas ainda necessitam sofrer ajustes para uma produção em escala industrial. A primeira usina brasileira é uma unidade da empresa GranBio (100\% brasileira) e fica localizada em São Miguel dos Campos, Alagoas. A Bioflex 1 tem capacidade de geração de $61 \mathrm{MWh}$ de energia por ano e o combustível produzido é considerado o mais limpo do mundo em intensidade de carbono.

O Brasil apresenta uma série de vantagens para a produção de etanol 2G como clima e solo apropriados, um grande conhecimento no cultivo de cana-de-açúcar e quatro décadas já utilizando e produzindo etanol como combustível, ou seja, a nossa frota de veículos já está adaptada. Além disso, a própria produção de etanol através da cana é considerada o melhor cenário para o etanol $2 \mathrm{G}$, isto porque dois terços da energia contida na cana não são convertidos em etanol ficando retidos no bagasso. A cana-energia torna-se então a biomassa mais produtiva para o bioetanol.

\section{Metodologia}

Através dos dados obtidos pelas últimas pesquisas realizadas, deseja-se fazer uma análise da sustentabilidade do uso de etanol 2G frente aos outros combustíveis convencionais de origem fóssil ou mesmo outros biocombustíveis. Além disso, também será analisada os impactos de sua inserção na matriz energética nacional. É importante destacar que a análise de sustentabilidade estará fundamentada no estudo dos aspectos: ambiental, social, econômico e logístico

\section{Materias e Métodos}

\subsection{Análise Ambiental}


A produção do etanol de cana-de-açúcar rende atualmente nove vezes mais energia do que consome. Isso é fundamental para a crescente necessidade de redução do uso de combustíveis fósseis no mundo. O etanol de segunda geração faz-se importante a partir do momento em que apresenta um maior rendimento, melhor uso da terra, colheita mecanizada, impactos ambientais expressivamente menores, maior variabilidade de biomassas utilizadas e um maior número de países capazes de produzi-lo. Além disso, a difusão do seu uso implicaria em uma redução na emissão de GEE e consequentemente um avanço nas lutas contra as mudanças climáticas, uso da terra e de recursos fósseis.

Os principais impactos ambientais gerados no ciclo produtivo do etanol de segunda geração é a poluição atmosférica local derivada tanto da queima da cana e do bagaço, como do uso do etanol $2 \mathrm{G}$ como combustível, que juntos emitem material particulado, monóxido de carbono, metano, óxidos de nitrogênio e aldeídos. Apesar de ser um impacto menor em relação aos combustíveis fósseis, ele ainda existe

No Brasil, visto que, a matéria-prima utilizada seria um coproduto do ciclo produtivo do etanol de primeira geração, nós estaríamos evitando a degradação do solo e a perda de terras pelo uso extensivo da cultura de cana sobre áreas de preservação permanentes e reserva legal, além da redução do uso de defensivos agrícolas e fertilizantes, destruição do ecossistema, entre outros.

Na produção de etanol $2 \mathrm{G}$ a colheita da cana não pode ser feita pela forma tradicional (queimadas), sendo assim, torna-se necessária a mecanização da colheita. Este fator traz consigo um ganho ambiental, visto que um dos principais impactos ambientais da cultura da cana está associado à queima da palha. Esta prática afeta o solo, mudando suas características físicas, altera a concentração de gases, reduz a fertilidade e a umidade do solo, leva a perda de nutrientes voláteis e a exposição do terreno aos efeitos erosivos. Além disso, existem inúmeras consequências para o ser humano como o risco de acidentes, problemas respiratórios causados pela inalação de fumaça e fuligem. A não prática da queima também faz com que a palha 
residual se deposite no solo formando uma cobertura que reduz a erosão e possibilita a formação de uma comunidade biológica que atua na decomposição da palha, além de ajudar no controle de ervas daninhas.

\subsection{Análise Social}

Em seu processo produtivo, o E2G necessita de mão-de-obra qualificada para operação da planta e da máquina colhedora. Este fato causa um impacto direto na geração de empregos deste setor (tabela 1), visto que, ainda utiliza-se mão-de-obra barata no corte manual da cana. A queima é uma prática que apesar de dominante até então, vem sendo reduzida devido às restrições ambientais.

No período de colheita da cana, o sistema tradicional ainda é utilizado em cerca de $70 \%$ das áreas cultivadas no Brasil (BNDES, 2008) e envolve a queima prévia do canavial e o corte manual da cana inteira. A queima é realizada para facilitar a colheita, reduzindo o tempo e aumentando a produtividade, eliminando as folhas e livrando a plantação de pragas e microorganismos que podem por em risco a vida dos operários, além disso reduz o volume para transporte. Porém estes dados vêm se alterando nos últimos anos, com a mecanização aumentando sua participação principalmente nos estados de São Paulo, Mato Grosso do Sul e Minas Gerais.

Tabela 1: Relação mecanização x empregos no campo.

\begin{tabular}{ccc}
\hline & $\mathbf{2 0 0 6 / 2 0 0 7}$ & $\mathbf{2 0 2 0 / 2 0 2 1}$ \\
\hline Produção de cana-de-açúcar (Mt) & 299 & 544 \\
\hline Área mecanizada & $40 \%$ & $100 \%$ \\
\hline Empregos - colheita manual & 189.600 & - \\
\hline Empregos - colheita mecânica & 15.500 & 70.800 \\
\hline Total & 55.300 & 75.300 \\
\hline
\end{tabular}

Fonte: CGEE, 2008. 


\subsection{Análise Econômica}

A precificação do bioetanol é determinada pelo preço do produtor, que por sua vez, são definidos de acordo com suas cadeias produtivas e logísticas, incorporando os tributos fiscais e lucros comerciais, sendo assim, é necessário analisar esse aspecto para avaliar sua viabilidade no mercado e seus impactos.

A produção de bioetanol pode ser feita com diversos tipos de matériaprima, cada uma gerando um custo de produção e um valor final de mercado. O preço mínimo para os produtores deve atender os custos de produção e ser igual ou superior aos resultados obtidos caso se produzisse um produto alternativo, neste caso, basicamente açúcar e melaço.

Em relação aos aspectos econômicos encontra-se no Brasil a vantagem de uma biomassa de baixo custo, na qual o país apresenta uma experiência produtiva secular, não necessitando assim, concentrar recursos para o desenvolvimento de biomassas economicamente viáveis para a produção do etanol de $2 \mathrm{G}$. Além disso, o país já apresenta uma ampla rede de distribuição de etanol e cultura de uso de veículos flex fluel.

Independente da rota tecnológica o custo da biomassa apresenta um enorme peso no custo final do etanol celulósico. Para países do hemisfério Norte, este custo chega a $40 \%$ (tabela 2), fazendo com que haja um intensivo esforço em reduzir o valor da biomassa. No Brasil, a biomassa da cana apresenta um custo muito reduzido, 1 US $\$ / G$ para a palha e custo zero para o bagaço.

Para o etanol 2G, alguns dos grandes gargalos são o alto custo operacional com enzimas, custo para a integração de processos, custo dos catalisadores, dificuldade na produção em grande escala e dificuldade de scale up da etapa de hidrólise. Existe também uma questão em torno da quantidade ideal do uso do bagaço para cogeração e para o etanol $2 \mathrm{G}$, e qual deles geraria uma maior rentabilidade.

Os estudos de viabilidade técnico-econômico necessários para responder estes questionamentos ainda não foram conclusivos no Brasil. 
Sendo assim, a maior parte dos dados obtidos e usados neste artigo se deram através de pesquisas realizadas nos EUA e na Europa.

Tabela 2: Descrição dos custos de produção do etanol lignocelulósico nos EUA e Europa.

\begin{tabular}{|c|c|c|c|c|}
\hline Referência & Matéria-prima & Processo & $\begin{array}{l}\text { Custo } \\
\text { (US\$.L-1) }\end{array}$ & $\begin{array}{l}\text { Capacidade } \\
\left(10^{6}\right. \\
\text { L.ano-1) }\end{array}$ \\
\hline \multirow{2}{*}{$\begin{array}{l}\text { Badger Engineers, } 1987 \\
\text { EUA }\end{array}$} & \multirow[t]{2}{*}{ Madeira dura } & \multirow[t]{2}{*}{ Hidrólise ácida } & 0,32 & 6,59 \\
\hline & & & 0,43 & 1,32 \\
\hline $\begin{array}{l}\text { Stone \& Webster } \\
\text { Engineering Corp., } 1987 \\
\text { EUA }\end{array}$ & Madeira de eucalipto & Hidrólise enzimática & 0,92 & 3,96 \\
\hline $\begin{array}{l}\text { Chem Systems, Inc., } \\
1987 \\
\text { EUA }\end{array}$ & $\begin{array}{l}80 \% \text { de madeira dura } \\
\text { e } 20 \% \text { de maple } \\
\text { (Plátano bastardo - Acer } \\
\text { pseudoplatanus) }\end{array}$ & $\begin{array}{l}\text { Hidrólise e fermentação } \\
\text { com produção de enzimas, } \\
\text { recuperação do } \mathrm{CO}_{2}\end{array}$ & 0,54 & 6,59 \\
\hline Sassner, 2008 - Europa & $\begin{array}{l}\text { Madeira de coníferas } \\
\text { (abeto) } \\
\text { Madeira dura (salgueiro) } \\
\text { Resíduos de milho }\end{array}$ & $\begin{array}{l}\text { Catalizado por } \mathrm{SO}_{2} \text {, explosão } \\
\text { a vapor, pré-tratamento, } \\
\text { sacarificação e fermentação } \\
\text { simultânea. }\end{array}$ & $\begin{array}{l}0,69 \\
0,86 \\
0,87\end{array}$ & $\begin{array}{l}200.000 \\
\text { ton de } \\
\text { biomassa } \\
\text { seca.ano-1 }\end{array}$ \\
\hline
\end{tabular}

Fonte: BNDES, 2014.

Os custos para a produção de etanol celulósico ainda são poucos competitivos frente ao custo de produção do etanol de primeira geração, principalmente devido à necessidade de aprimoramento das tecnologias em desenvolvimento, estudos detalhados de escala, produção regional e viabilidade técnico-econômica.

Dificilmente, o bioetanol poderá ser inserido no mercado energético de um país sem um suporte governamental e com a adoção de um marco tributário específico, proporcionando estímulos suficientes para que os riscos sejam superados e a cadeia produtiva e distributiva avance chegando ao consumidor.

Nos últimos anos, o preço do etanol perdeu competitividade frente ao preço da gasolina. A crise econômica mundial de 2008 impactou seriamente o setor, que já se encontrava altamente endividado, após um período de grande investimento em novas unidades. Por outro lado, os governos dos Estados Unidos e União Europeia, maiores importadores e ainda com potencial crescimento, incentivaram a produção interna de biocombustíveis, dependendo cada vez menos do etanol brasileiro. Além disso, lançaram legislações específicas e estabeleceram barreiras tarifárias à entrada do etanol em seus 


\section{Periódica Eletrônica

mercados. No Brasil, em decorrência disso, houve restrição ao crédito interno e externo.

As dívidas acumuladas obrigaram as empresas a reduzir investimentos e despesas para equilibrar seus orçamentos. Neste sentido elas adiaram a expansão e renovação dos canaviais, e não realizaram os tratos culturais adequadamente. Com a redução da produtividade, o volume de cana produzido nas safras seguintes caiu, provocando ociosidade no processamento das unidades industriais. Sendo assim, de 2008 a 2010 há aumento da cana soca, redução de reforma e da taxa de expansão, e o envelhecimento do canavial (menor produtividade).

Além disso, o clima pouco favorável, com chuvas excessivas em 2009 e secas no final de 2010 e de 2011, agravaram a situação. A conjugação de tantos fatores negativos elevou os custos de produção, proporcionando a perda de competitividade em relação à gasolina. Paralelamente, houve um maior direcionamento do setor para a produção de açúcar, devido a sua melhor remuneração no mercado internacional.

\subsection{Logística do etanol}

Em muitos países se reconhece a importância do etanol para a matriz energética, porém são apresentados obstáculos na infraestrutura e carência de recursos para a sua implementação. As condições de armazenamento e transporte não diferem muito daquelas ligadas aos combustíveis fósseis, mas três fatores devem ser considerados: a sazonalidade da produção, a dispersão espacial da produção e a compatibilidade dos tanques e tubulações que entram em contato com o etanol produzido.

Não se pode armazenar a cana-de-açúcar colhida manualmente por mais do que alguns dias, ou seja, apenas durante os meses de colheita ocorre produção de etanol que é consumido regularmente ao longo de todo ano. São necessárias safras mais longas que permitam maior utilização da capacidade de produção instalada e menor necessidade de armazenamento durante 0 período que não tiver colheita. Dessa forma é interessante a adoção da 
produção de bioetanol a partir de outras matérias-primas que permitam seu armazenamento.

Além das variações de produção e demanda, diversos fatores geram incertezas, destacando-se nitidamente os climáticos. Recomenda-se um estoque de produção para eventuais contingencias. Uma das formas de se ajustar à essas incertezas, é a variação no teor de etanol presente na gasolina, o que já é feito pelo governo brasileiro. O etanol é ajustado numa faixa de $20 \%$ $25 \%$ sem comprometer os motores de combustão.

O etanol é recebido das usinas produtoras por rodovias e despachado através dos meios mais econômicos para os terminais e bases distribuidoras onde se realizam a mistura com gasolina, e a partir desse ponto é distribuído para bases secundárias ou diretamente aos revendedores. A maior parte da distribuição ocorre por meio de rodovias através de caminhões tanque com capacidade de até 60.000 litros.

Experiências em outros países mostram que as maiores dificuldades foram associadas a limitações logísticas, pela falta de estrutura, transporte e armazenamento. Tais experiências demonstram a necessidade de se implementar esses programas em etapas, reforçando progressivamente suas capacidades como forma de consolidá-lo.

Dois fatores diferenciam o Brasil do resto do mundo e o torna um cenário único: a ampla cobertura geográfica e o elevado número de postos de abastecimento que comercializam o produto. É importante reconhecer que sem os incentivos políticos e fiscais para garantir tal estrutura e o apoio das empresas de distribuição, a experiência brasileira não teria alcançado os patamares atuais.

\subsection{Emissões e balanço energético}

Independentemente da biomassa utilizada durante sua produção, o objetivo principal do bioetanol é a redução da necessidade de utilização dos combustíveis derivados de petróleo, diminuindo a dependência por tais recursos e consequentemente diminuindo a emissão dos gases do efeito 
estufa. Porém, para um biocombustível substituir um combustível fóssil, depende da maneira em que o mesmo é produzido. Como as tecnologias de produção dependem diretamente ou indiretamente dos recursos fósseis, o benefício depende da economia efetiva de energia não renovável que ele proporciona quando comparado ao seu equivalente fóssil.

Para calcular as necessidades energéticas no processo agroindustrial, devem ser consideradas as emissões dos gases associadas ao seu ciclo de vida em todas as fases produtivas, como também dos insumos produtivos. A princípio, todo o dióxido de carbono liberado na queima é reciclado por meio da fotossíntese no crescimento da biomassa no próximo ciclo produtivo, mas a parcela consumida na produção de bioetanol gera um acréscimo liquido na quantidade desses gases na atmosfera.

Mais estudos e pesquisas são necessários para entender a real contribuição da quantidade de emissão de carbono na atmosfera. No Brasil, a expansão do etanol está associada a pouca perda de cobertura vegetal, visto que as áreas utilizadas foram antes ocupadas por pastagens de baixa produtividade ou relacionadas a atividades com baixa retenção de carbono quando comparada a realizada pela cana-de-açúcar.

Estudos mostram que para cada unidade de energia fóssil utilizada na produção do bioetanol da cana, mais de nove unidades de energia renováveis são produzidas na forma de bioetanol e excedentes de energia elétrica e bagaço. Mesmo com a mecanização e tecnologias agrícolas que devem ampliar a demanda energética em 12\%, o incremento da produção de bioetanol por tonelada de cana processada, deve permitir que a agroindústria da canade-açúcar se mantenha como a forma mais eficiente de produzir biocombustível e bioeletricidade.

\subsection{Perspectivas para o setor sucoenergético}

Estudos confirmam que nos próximos 20 anos o setor sucroenergético passará por uma transição com o objetivo de atingir e aperfeiçoar a cadeia produtiva de etanol, energia e bioprodutos, através de uma melhor 


\section{Periódica Eletrânica \\ Fórum Ambiental}

da Alta Paulista
Volume 11, Número 09, 2015

Produção e as

Tecnologias Sustentáveis

compreensão de suas vantagens competitivas no âmbito social, econômico e ambiental. O foco será atingir uma liderança internacional e domínio tecnológico do ciclo produtivo. Segundo a UNICA (União da Indústria de Canade-açúcar), a bioeletricidade apresenta um potencial de suprir cerca de $15 \%$ de toda a demanda de eletricidade do país até o final da década.

$O$ etanol $2 G$ possui grande potencial para diversificar a matriz energética brasileira e melhorar a segurança no sistema elétrico nacional uma vez que se apresenta como fonte renovável de energia, podendo ser utilizado nas usinas, em caldeiras para geração de calor e eletricidade, no processo de fabricação do álcool e do açúcar e, principalmente na geração de excedentes de energia elétrica, que podem ser comercializados (GOES et al, 2009).

Além disso, o biocombustível representa um produto com enorme potencial competitivo no futuro devido a crescente redução de reservas de petróleo. A preocupação com a segurança energética é uma realidade em todo o mundo e o Brasil possui a oportunidade de se consolidar e ser uma referência mundial ainda maior no setor sucroenergético.

Visando atender esses objetivos é preciso investir em melhoramento genético, manejo da cultura, hidrólise e termoconversão. Na tabela 3 encontram-se descritos as metas para alcançar cada um desses componentes tecnológicos. A produtividade pode ser ampliada com o uso de outras culturas (sorgo sacarino, mandioca, dentre outras) no período de entressafra. Desta forma, pode-se garantir a oferta de etanol ao longo do ano, evitando-se o aumento de preços e desabastecimento.

No Brasil os investimentos em tecnologia para a produção de etanol têm aumentando consideravelmente, mas ainda continuam pequenos em relação às iniciativas americanas e europeias (tabela Paralelamente, há uma dedicação das principais instituições como a UFRJ, CTC, CTBE e Embrapa em pesquisa. Apesar disso, o esforço brasileiro peca na capacidade de coordenação. A multiplicidade de fontes públicas de fomento e de instituições de pesquisa implica na pulverização de recursos e concentração do apoio em linhas de pesquisa já maduras em detrimento dos projetos de pesquisa nas novas rotas de conversão de biocombustíveis. 
O governo americano já vem fazendo um investimento maciço no setor, sua maior produtora de etanol, a Poet, já possui tecnologia avançada para produção comercial e anunciou para 2022 a produção de 13,2 bilhões de litros de etanol celulósico por ano.

Segundo Kohlhepp (2010), a segunda geração de biocombustíveis pode representar, a partir da próxima década, uma produtividade 40\%-50\% maior, o que pode ser fundamental para a redução dos conflitos socioambientais.

\section{Conclusão}

De acordo com as análises dos aspectos sociais, ambientais, econômico e logísticos discutidos, o Brasil apresenta um grande potencial na produção de biocombustíveis, em particular o do etanol de segunda geração. Apesar da maior capacidade de articulação e da disponibilidade de recursos financeiros dos EUA e da UE, aqui encontra-se de forma mais bem equacionada a questão da economicidade da biomassa para novas rotas de conversão.

A melhor disponibilidade de biomassa à baixo custo aliado a um apoio mais eficiente para o desenvolvimento de novas técnicas de conversão, poderiam levar o Brasil à condição de pioneiro na produção de etanol celulósico e de outros biocombustíveis. Por isso, torna-se necessário o aperfeiçoamento do modelo de apoio das agências federais à PD\&l de biocombustíveis. Dentre os pontos que precisam ser alterados estão: o aumento da disponibilidade e previsibilidade de recursos, melhor coordenação de agências de fomento federais, construção de um modelo de fomento coordenado e uma maior focalização em projetos de biocombustíveis avançados.

O futuro do setor sucroenergético depende diretamente do incentivo às pesquisas e desenvolvimento de novas tecnologias e melhoria das já em curso. A palha não queimada tem grande potencial, entretanto, necessita de políticas públicas para que se estabeleça de forma competitiva no mercado. 


\section{Referências Bibliográficas}

BNDES e CGEE. Bioetanol de cana-de-açúcar: energia para o desenvolvimento sustentável. Rio de Janeiro. BNDES, 2008.

BNDES. O BNDES em um Brasil em transicao BNDES. A corrida tecnológica pelos biocombustíveis de 2G, 2014.

CenBio. Aspectos Ambientais, Sociais e Econômicos do Etanol de Segunda Geração, 2009.

CGEE . Bioetanol de Cana-de-Açúcar - Energia para o Desenvolvimento Sustentável, 2008.

CGEE. Sustainabily of sugarcane bioenergy, 2012.

GOES, Tarcizio et al. (2009). Novas fronteiras tecnológicas da cana-de-açúcar no Brasil. Revista de Política Agrícola. Brasília: Janeiro, Fevereiro e Março, n.1.

KOHLHEPP, Gerd. Análise da situação da produção de etanol e biodiesel no Brasil. Estud. av., São Paulo, v. 24, n. 68, p. 223-253, 2010.

MANZATTO, C. V.; ASSAD, E. D.; BACA, J. F. M.; ZARONI, M. J.; PEREIRA, S. E. M. Zoneamento Ecológico da cana-de-açúcar. Embrapa Solos, 2009.

Site http://www.unica.com.br/. Consultado em maio de 2015. 